\title{
Selective Increase of the Permeability of Polarized Epithelial Cell Monolayers by Helicobacter pylori Vacuolating Toxin
}

\author{
Emanuele Papini, ${ }^{\star}$ Barbara Satin, ${ }^{*}$ Nathalie Norais, ${ }^{\ddagger}$ Marina de Bernard, ${ }^{*}$ John L. Telford, ${ }^{\ddagger}$ Rino Rappuoli, ${ }^{\ddagger}$ \\ and Cesare Montecucco* \\ *Centro CNR Biomembrane and Dipartimento di Scienze, Biomediche, Università di Padova, 35121 Padova, Italy; and ${ }^{\ddagger}$ Centro di \\ Ricerche I.R.I.S., CHIRON-Biocine, 53100 Siena, Italy
}

\begin{abstract}
The effects of the vacuolating toxin (VacA) released by pathogenic strains of Helicobacter pylori on several polarized epithelial monolayers were investigated. Trans-epithelial electric resistance (TER) of monolayers formed by canine kidney MDCK I, human gut T84, and murine mammary gland epH4, was lowered by acid-activated VacA. Independent of the cell type and of the starting TER value, VacA reduced it to a minimal value of 1,000-1,300 $\Omega \times$ $\mathrm{cm}^{2}$. TER decrease was paralleled by a three- to fourfold increase of $\left[{ }^{14} \mathrm{C}\right]$-mannitol (molecular weight 182.2) and a twofold increase of $\left[{ }^{14} \mathrm{C}\right]$-sucrose (molecular weight 342.3) transmonolayer flux. On the contrary, transmembrane flux of the proinflammatory model tripeptide $\left[{ }^{14} \mathrm{C}\right]-\mathrm{N}$-formylMet-Leu-Phe (molecular weight 437.6), of $\left[{ }^{3} \mathrm{H}\right]$-inuline (molecular weight 5,000) and of HRP (molecular weight 47,000) did not change. These data indicate that VacA increases paracellular epithelial permeability to molecules with molecular weight $<350-440$. Accordingly, the epithelial permeability of $\mathrm{Fe}^{3+}$ and $\mathrm{Ni}^{2+}$ ions, essential for $\mathrm{H}$. pylori survival in vivo, was also increased by VacA. High-resolution immunofluorescence and SDS-PAGE analysis failed to reveal alterations of junctional proteins ZO-1, occludin, cingulin, and E-cadherin. It is proposed that induction by VacA of a selective permeabilization of the epithelial paracellular route to low molecular weight molecules and ions may serve to supply nutrients, which favor $H$. pylori growth in vivo. (J. Clin. Invest. 1998. 102:813-820.) Key words: vacuolating toxin - Helicobacter pylori - tight junctions • gastritis • gastric ulcer
\end{abstract}

\section{Introduction}

There is a strong correlation between protracted stomach infection by the gram negative bacterium Helicobacter pylori and the pathogenesis of gastritis and gastroduodenal ulcer (1$3)$. More recently, $H$. pylori has been associated to an increased risk of developing gastric adenocarcinoma and MALT

Address correspondence to Dr. Emanuele Papini, Dipartimento di Scienze Biomediche, Università di Padova, Via G. Colombo n. 3, 35121 Padova, Italy. Phone: +39 49 8276077; FAX: +39 49 8276049; E-mail:papinie@civ.bio.unipd.it

Received for publication 7 January 1998 and accepted in revised form 22 June 1998.

J. Clin. Invest.

(C) The American Society for Clinical Investigation, Inc. 0021-9738/98/08/0813/08 \$2.00

Volume 102, Number 4, August 1998, 813-820

http://www.jci.org lymphomas $(3,4)$. H. pylori strains isolated from patients suffering of severe gastritis and gastroduodenal ulcers almost invariably express a cytotoxin $(\mathrm{VacA})^{1}$ and a toxin-associated antigen (CagA) (5) marker of a 40-kb pathogenicity island (6). CagA is the major antigen in $H$. pylori seropositive patients (7), and it is related to the induction of IL-8 in vivo (8). Cultured cells exposed to purified VacA develop membrane bound vacuoles, which originate in the perinuclear area, grow in number and size, and occupy the entire cytoplasm $(9,10)$. Such vacuoles are endowed with the vacuolar proton pump (V-ATPase), sensitive to bafilomycin A1 (11-14), and are highly enriched in both the small GTP-binding protein rab7 (15) and the lysosomal membrane protein lgp120 (16). Both $\mathrm{V}$-ATPase and rab7 function are required for vacuole formation and enlargement (17). Before any macroscopic vacuolation is apparent, VacA inhibits endolysosomal proteolysis, antigen processing, and intracellular targeting and retention of lysosomal hydrolases precursors, by partial neutralization of acidic intracellular compartments $(18,19)$. Based on these findings, vacuoles were proposed to originate from a specific alteration of late endosomal/prelysosomal compartments.

VacA is synthesized as a $140-\mathrm{kD}$ precursor, is processed after export from the outer membrane into a mature $95-\mathrm{kD}$ protein, and is released in the medium where it assembles into high molecular weight oligomers (20). VacA shows the remarkable property of being strongly activated by, and of being resistant to, $\mathrm{pH}$ values as low as 1.5 (21). Acid-activated VacA has a different structure from the nonacid exposed toxin (21, 22). Yet uncharacterized H. pylori protease(s) cleaves VacA within a repeated segment and generates a C-terminal fragment of $58 \mathrm{kD}$ (p58) and a N-terminal fragment of $37 \mathrm{kD}$ (p37) (23). This hints at the possibility that VacA belongs to the A-B type bacterial toxins acting on intracellular targets. In these toxins, the protomer $\mathrm{B}$ binds to a plasma membrane receptor and mediates the translocation of the catalytic protomer $\mathrm{A}$ subunit into the cytosol (24).

Little is known about the effect of VacA on epithelial gastric cells in vivo, its role on the pathogenesis of gastroduodenal diseases, or on bacteria-host interactions. It is likely that VacA is released by infecting bacteria near the apical membrane of gastric epithelial cells. Therefore, polarized epithelial monolayers are more appropriate cellular systems to study its action than sparse nonpolarized cells. Moreover, such cellular system allows one to test the hypothesis that VacA contributes to $H$. pylori survival by inducing a flow of ions and nutrients from under the mucosa toward the stomach lumen, as a consequence of an alteration of the gastric epithelium integrity (2). Several cell lines form stable monolayers characterized by two functionally distinct membrane domains, the apical and the ba-

1. Abbreviations used in this paper: TER, transepithelial electric resistance; TJ, tight junction; VacA, vacuolating toxin. 
solateral one, and by specialized intercellular adhesion complexes (25). Among them, tight junctions (TJs) are expected to play a major role as barriers to the flow of ions, metabolites, proteins, and pathogens between the upper and lower compartments $(26,27)$.

Here, we report on the action of purified VacA on several epithelial cell monolayers characterized by different transepithelial electric resistance (TER) values (28-31). VacA lowers their transepithelial resistance, at the same time increasing their paracellular permeability to small organic molecules with a molecular weight $<350-450$ and to ions, including $\mathrm{Fe}^{3+}$ and $\mathrm{Ni}^{2+}$, which are essential for $H$. pylori growth. This effect was induced with no sign of acute cytotoxicity, intercellular junction disruption and intracellular vacuolation. Based on these data, we suggest that one role of VacA in vivo is to increase the supply of nutrients to $H$. pylori from the undermucosal compartment.

\section{Methods}

Reagents. VacA was purified from the CCUG 17874 H. pylori strain, as described (32), and stored at $4^{\circ} \mathrm{C}$ in PBS at the concentration of $0.1-0.2 \mathrm{mg} / \mathrm{ml}$. When indicated, the toxin was pretreated for $5 \mathrm{~min}$ at $37^{\circ} \mathrm{C}$ at $\mathrm{pH}$ values ranging from 6.0 to 2.0 , obtained by addition of previously tested amounts of a $100-\mathrm{mM}$ hydrochloride acid solution (21). Bolton \& Hunter reagent for protein ${ }^{125}$ I-iodination was from Amersham International (Buckinghamshire, England). Human recombinant EGF, bumetanide, sodium gluconate, neutral red, and toluidine blue were from Sigma (St. Louis, MO). ${ }^{59} \mathrm{Fe}^{3+}(18.5 \mathrm{mCi} /$ $\mathrm{mmol}),{ }^{63} \mathrm{Ni}^{2+}(9.79 \mathrm{mCi} / \mathrm{mmol}),\left[{ }^{14} \mathrm{C}\right]-$ mannitol $(60 \mathrm{mCi} / \mathrm{mmol}),\left[{ }^{14} \mathrm{C}\right]-$ sucrose $(0.672 \mathrm{Ci} / \mathrm{mmol}),\left[{ }^{14} \mathrm{C}\right]$-FMLP $(61 \mathrm{Ci} / \mathrm{mmol})$, and $\left[{ }^{3} \mathrm{H}\right]$-inulin $(0.74 \mathrm{Ci} / \mathrm{ml})$ were from NEN (Bruxelles, Belgium). Bafilomycin A1 was a kind gift of Dr. K. Altendorf (University of Osnabruck, Osnabruck, Germany). Rabbit polyclonal antibodies to ZO-1 and occludin were from Zymed (S. San Francisco, CA). Mouse monoclonal antibody to E-cadherin was from Transduction Laboratories. Rabbit polyclonal antibody to cingulin was a kind gift of S. Citi (University of Padova, Padova, Italy). Ouabain, FITC and Rhodaminated antibodies to rabbit or mouse antibodies were from Sigma. FCS was from Bouty (West Grove, PA). All other reagents used were of the highest purity available.

Cells. MDCK I, T84, Caco-2, epH4, and HeLa cells were cultured at $37^{\circ} \mathrm{C}$ on plastic flasks in DMEM, supplemented with $10 \%$ ( $\mathrm{vol} / \mathrm{vol}$ ) FCS and gentamycine $(50 \mu \mathrm{g} / \mathrm{ml})$ in a $5 \% \mathrm{CO}_{2}$ humidified atmosphere. To form monolayers, cells were suspended with trypsinEDTA, and seeded on cellulose Transwell porous filters (pore diameter $0.4 \mu \mathrm{m}$; Costar, Cambridge, MA), at the density of $0.6 \times 10^{6} / \mathrm{cm}^{2}$. The medium of the upper and lower filter chambers were changed every $24 \mathrm{~h}$, and the formation of a stable monolayer was assessed by monitoring the TER.

Measurements of cell monolayers permeability. The TER was measured at $37^{\circ} \mathrm{C}$ with a Millipore apparatus. In each filter, TER value was determined as the mean of three measurements performed at equivalent positions. After subtraction of the bare filter resistance, the TER value was multiplied for the filter surface and expressed as $\Omega \times \mathrm{cm}^{2}$. When indicated, cells were pretreated for $30 \mathrm{~min}$ with $20 \mu \mathrm{M}$ bumetanide added to the lower filter chamber before VacA addition to the apical filter chamber. In some experiments, VacA effect was determined in $10 \mathrm{mM}$ NaHepes, $\mathrm{pH} 7.4$, containing $135 \mathrm{mM} \mathrm{NaCl}$, $5 \mathrm{mM} \mathrm{KCl}, 1 \mathrm{mM} \mathrm{CaCl}$, and $1 \mathrm{mM} \mathrm{MgCl}_{2}$ or $10 \mathrm{mM} \mathrm{NaHepes,} \mathrm{pH}$ 7.4, containing $135 \mathrm{mM}$ Na-gluconate, $5 \mathrm{mM} \mathrm{K}$-gluconate, $1 \mathrm{mM}$ $\mathrm{CaCl}_{2}$, and $1 \mathrm{mM} \mathrm{MgCl}$. In some experiments, ${ }^{62} \mathrm{Ni}^{2+}(4.4 \mu \mathrm{Ci} / \mathrm{ml})$, ${ }^{59} \mathrm{Fe}^{3+}(1.6 \mu \mathrm{Ci} / \mathrm{ml}),\left[{ }^{14} \mathrm{C}\right]$-mannitol $(0.25 \mu \mathrm{Ci} / \mathrm{ml}),\left[{ }^{14} \mathrm{C}\right]$-sucrose $(20$ $\mu \mathrm{Ci} / \mathrm{ml}),\left[{ }^{14} \mathrm{C}\right]$-f-MLP $(2 \mu \mathrm{Ci} / \mathrm{ml}),\left[{ }^{3} \mathrm{H}\right]$-inulin $(20 \mu \mathrm{Ci} / \mathrm{ml})$, and horseradish peroxide $(0.2 \mathrm{mg} / \mathrm{ml})$ were added to the lower chamber me- dium. The radioactivity in the upper chamber was determined at time intervals either by liquid scintillation or by $\gamma$-counting, while horseradish peroxide activity was determined as described (33).

Neutral red uptake and ${ }^{125}$ I-EGF degradation. After intoxication with VacA, HeLa cells, MDCK, and T84 cell monolayers were washed with PBS plus $0.3 \%$ BSA and further incubated with $8 \mathrm{mM}$ neutral red in the same buffer for $8 \mathrm{~min}$ at room temperature. After several washes with PBS containing $0.3 \%$ BSA, neutral red was extracted from cells with $70 \%$ ( vol $/ \mathrm{vol}$ ) ethanol and, $0.37 \%$ (wt $/ \mathrm{vol})$ hydrochloric acid, and its absorbance at $540 \mathrm{~nm}$ was determined. Blank corresponded to cells pretreated with $1 \mu \mathrm{M}$ bafilomycin $\mathrm{A}_{1}$ for $2 \mathrm{~h}$, while cells not treated with VacA represented controls. Absorbance values were expressed as relative increase with respect to controls, after blank subtraction. Alternatively polarized or nonpolarized sparse cells were treated with VacA, treated with neutral red, and photographed with a Zeiss Axioplan microscope (Jena, Germany).

${ }^{125}$ I-epidermal growth factor (50 $\mathrm{nM}$ in DMEM, 0.3\% [wt/vol] BSA) was added to HeLa cells or to the lower chamber medium of MDCK and T84 monolayers at $37^{\circ} \mathrm{C}$. After $15 \mathrm{~min}$, cells were washed with and further incubated in DMEM, $0.3 \%$ (wt $/ \mathrm{vol}$ ) BSA at $37^{\circ} \mathrm{C}$. TCA soluble or nonsoluble radioactivity was determined in the extracellular medium (in both the upper and lower chamber media in the case of cell monolayers) in the following hour (18). The rate of EGF degradation was expressed as percentage of the value obtained in control cells.

Immunofluorescence. MDCK monolayers grown on cellulose filters were washed with PBS plus $1 \mathrm{mM} \mathrm{CaCl}_{2}$ and $1 \mathrm{mM} \mathrm{MgCl}_{2}\left(37^{\circ} \mathrm{C}\right)$ then fixed and permeabilized with methanol/acetone (50:50) for $5 \mathrm{~min}$ at $-20^{\circ} \mathrm{C}$. Filters were air dried, washed with TBST (Tris-Cl $100 \mathrm{mM}$, $\mathrm{pH} 8.0, \mathrm{NaCl} 50 \mathrm{mM}$, containing $0.05 \%$ Tween 80 ), cut out with a scalpel blade, and incubated with primary antibodies to ZO-1, occludin, cingulin, or E-cadherin for $1 \mathrm{~h}$. Filters were washed five times with TBST, $1 \%$ (wt/vol) BSA, for 5 min and incubated with FITC- or Rhodamine-conjugated antibody to anti-rabbit or mouse antibodies for $30 \mathrm{~min}$. After five washes with TBST, 1\% (wt/vol) BSA, filters were mounted in glycerol $90 \%$ (vol/vol) in PBS, containing 3\% (wt/ vol) propylgallate, with the cell monolayer upside down and covered with a glass cover slip sustained at each corner by nail varnish spots. Fluorescent optical sections $(0.5 \mu \mathrm{m})$ of cell monolayers were determined with a Axiovert TV-100 fluorescence microscope, equipped with a CD camera. Single XY planes (parallels to the filter surface) and reconstructed $\mathrm{XZ}$ planes (orthogonal to the filter surface) were obtained and processed using the Metamorph deconvolution software (Universal Imaging Corporation, West Chester, PA).

Miscellaneous. Protein concentration assay and SDS-PAGE were carried out as described $(34,35)$. For Western blot analysis, cells were dissolved in Laemmli sample buffer $(60 \mathrm{mM}$ Tris-acetate $\mathrm{pH}$ $6.8,8 \%$ SDS, glycerol $10 \%$ [vol $/ \mathrm{vol}]$, mercaptoethanol $5 \%$ [vol $/ \mathrm{vol}]$ ) and loaded on $10 \%$ polyacrylamide gels. Proteins were transferred to nitrocellulose, and antigens were detected with specific primary antibodies and with alkaline-phosphatase conjugated secondary antibodies. For toluidine blue staining cells, monolayers were incubated with $1 \%$ toluidine blue, $1 \% \mathrm{Na}_{2} \mathrm{~B}_{4} \mathrm{O}_{7}$ for $1 \mathrm{~h}$ at room temperature, and then washed four times with PBS and four times with $70 \%$ (vol/vol) ethanol.

\section{Results}

Effect of VacA on transepithelial monolayer resistance. Within 7-14 d from seeding on filters, MDCK, T84, and epH4 cells formed monolayers with TER values ranging from 2,500 to $17,000 \Omega \times \mathrm{cm}^{2}$, depending of the particular cell line, whereas Caco- 2 cells, in agreement with previous data, never reached TER values $>600-700 \Omega \times \mathrm{cm}^{2}$ (Fig. 1). Acid-activated VacA added to the apical side of cell monolayers caused a decrease of TER much larger than that caused by non-acid-exposed 


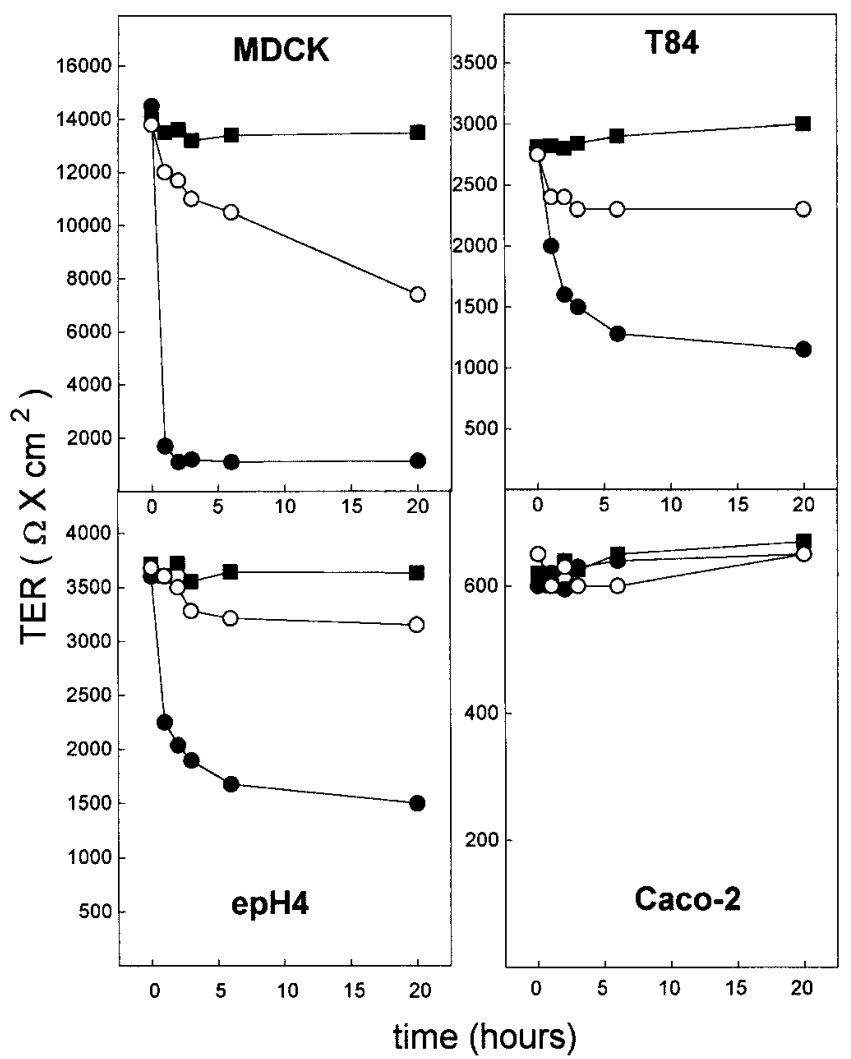

Figure 1. Effect of VacA on TER of MDCK, T84, epH4, and Caco-2 monolayers. Cell monolayers grown on collagen-coated cellulose filters were treated with $200 \mathrm{nM}$ VacA pretreated at $\mathrm{pH} 2.0$ (filled circles), at $\mathrm{pH} 7.4$ (open circles), applied to the upper chamber or with no toxin (filled squares). After different incubation times, TER was measured in three different positions, and the mean value obtained. Data correspond to a representative experiment.

toxin (Fig. 1). In MDCK cells, TER dropped from 17,00014,000 to $1,000-1,200 \Omega \times \mathrm{cm}^{2}$ within $<1 \mathrm{~h}$, while TER of T84 and epH4 monolayers decreased from 3,500-2,500 to 1,000$1,200 \Omega \times \mathrm{cm}^{2}$ in 5-7 h. No effect of VacA was apparent on Caco- 2 cell monolayers, whose initial resistance was always $<1,000 \Omega \times \mathrm{cm}^{2}$. TER values of 1,000-1,500 $\Omega \times \mathrm{cm}^{2}$ correspond to epithelial monolayers with assembled and functional
TJs (36). Hence, VacA does not cause a collapse of the cell monolayer, but rather a modulation of its permeability to ions. Regardless to the initial TER value and the cell type used, epithelial monolayers exposed to VacA always reached the same final TER value $\left(1,000-1,200 \Omega \times \mathrm{cm}^{2}\right)$, which remained stable over time. Further additions of maximal dose of activated VacA (200 nM) failed to further decrease TER (not shown). Visual inspection of control and VacA treated monolayers stained with toluidine blue confirmed the apparent integrity of the cell monolayer (not shown). No effects were noticed when VacA was added to the lower filter compartment, facing the basolateral membrane. This is due in part to a lower accessibility of the basolateral membrane to the toxin determined by the physical barrier of the filter; after $24 \mathrm{~h} \sim 10 \%$ of ${ }^{125} \mathrm{I}-\mathrm{VacA}$ added in the lower chamber redistributed to the apical compartment in the absence of cells (not shown).

Dose response and $\mathrm{pH}$ dependence of the effect of VacA on the transepithelial resistance of cell monolayers. Fig. $2 A$ shows the dose-response effect of VacA on the TER of MDCK and T84 cells; the IC50 value is $\sim 5-20 \mathrm{nM}$ VacA. Fig. 2 also reports the $\mathrm{pH}$ dependence of $\mathrm{VacA}$ activation with respect to its ability of lowering TER of MDCK and T84 monolayers $(B)$. In both cases, the toxin not exposed to low $\mathrm{pH}$ had a lower activity, and the range of $\mathrm{pH}$ values effective for activation was closely similar to that found previously for the induction of vacuoles in HeLa cells (29).

Effect of VacA on the permeability of epithelial cell monolayers to organic molecules with increasing molecular size. The membrane impermeable sugar mannitol molecular weight (182) can be used to probe alterations of the paracellular route in polarized epithelia (37). Fig. 3 shows that the permeability of MDCK and T84 cell monolayers incubated with acid-activated VacA to $\left[{ }^{14} \mathrm{C}\right]$-mannitol increased with respect to both mock-treated cells and cells treated with nonactivated VacA. For both cell lines, after a 1-1.5-hour lag phase, the increase in mannitol flow caused by VacA matched reasonably with changes in ion conductivity. No further decrease of TER values were noted in VacA-treated monolayers during the experiment.

The kinetics and final extent of TER decrease was not significantly affected either by treatment with bumetanide, a specific inhibitor of the $\mathrm{Na} / \mathrm{K} / 2 \mathrm{Cl}$ cotransporter (37), which allows the basolateral permeation of chloride and its subsequent secretion via apical membrane channels, or by replacing chloride

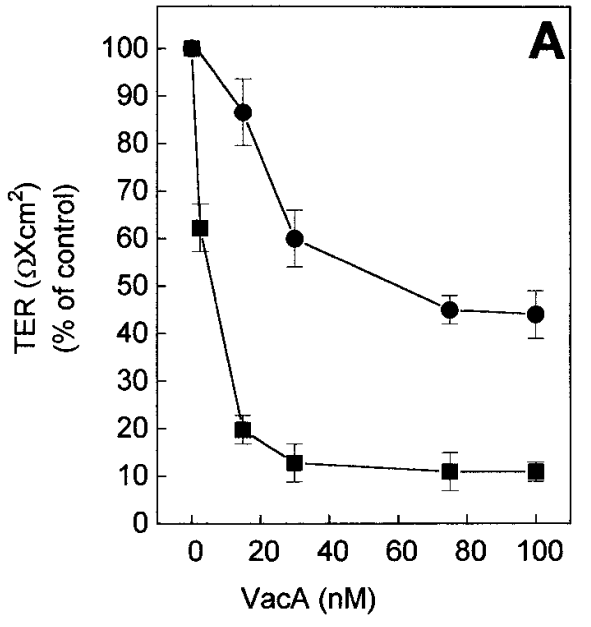

Figure 2. Dose response and $\mathrm{pH}$ dependence of TER variation induced by VacA. $(A) \mathrm{VacA}(10 \mu \mathrm{M})$ was activated by treatment at $\mathrm{pH} 2.0$, diluted to indicated concentrations and applied to the upper chamber of filter grown MDCK (filled squares) and T84 (filled circles) monolayers. $(B)$ VacA samples $(10 \mu \mathrm{M})$, were incubated at indicated $\mathrm{pH}$ values for $5 \mathrm{~min}$ at $37^{\circ} \mathrm{C}$, diluted to $200 \mathrm{nM}$ in DMEM, plus $10 \%$ FCS and added to the upper chamber of filters on which cell monolayers were grown. After $24 \mathrm{~h}$, TER was measured and expressed as percentage decrease relative to TER value of cell monolayers treated with no toxin. Data are the mean of three experiments, run in duplicate. Bars represent range. 


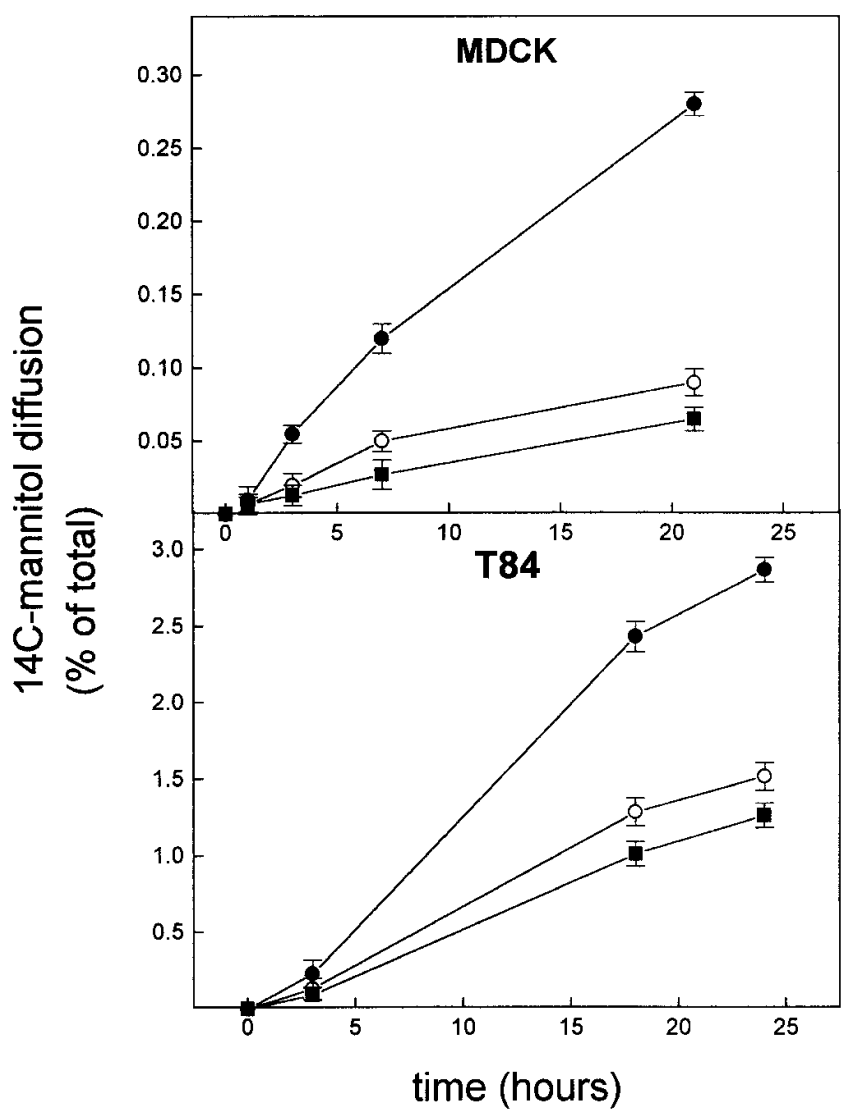

Figure 3. Increased diffusion of $\left[{ }^{14} \mathrm{C}\right]$-mannitol through monolayers of MDCK and T84 cells induced by VacA. Cell monolayers on cellulose filters were treated apically for $24 \mathrm{~h}$ with $200 \mathrm{nM}$ VacA (open circles), $200 \mathrm{nM}$ VacA pre-activated by exposure to $\mathrm{pH} 2.0$ (filled circles) or no toxin (filled squares). $\left[{ }^{14} \mathrm{C}\right]-\mathrm{Mannitol}(0.25 \mu \mathrm{Ci} / \mathrm{ml})$, was then added to the lower chamber in DMEM medium, without carbonate, plus $5 \% \mathrm{FCS}$ and $10 \mathrm{mM}$ Na-Hepes, $\mathrm{pH}$ 7.4. The rate of radioactivity efflux to the upper chamber was then determined. Data are the means of two experiments run in duplicate and bars represent range.

for the membrane impermeant anion gluconate in the extracellular medium (Fig. 4, $A$ and $B$ ). These data exclude that VacA-induced increase of epithelial permeability to ions is due to the opening of anion specific channels in the apical cell membrane. To assess the equivalent pore size of the alteration induced by VacA in the paracellular pathway, we quantified and compared the increase of epithelial permeability to mannitol (molecular weight 182), sucrose (molecular weight 342.3), f-MLP (molecular weight 437.6), inulin (molecular weight 5,000), and HRP (molecular weight 47,000).

As shown in Fig. $4 C$, increase of sucrose conductivity, induced by VacA, was sensibly smaller than that of mannitol, while transepithelial flux of f-MLP, inulin, and HRP was unaffected. Taken together, such results indicate that VacA facilitates the diffusion through the space between adjacent cells of molecules with molecular weight $<350-450$.

Figure 4. Effect of VacA on TER in the presence of the $\mathrm{Na} / \mathrm{K} / 2 \mathrm{Cl}$ cotransporter inhibitor bumetanide and extracellular gluconate and on transepithelial diffusion of different size molecules. $(A)$ MDCK cell monolayers were pretreated basolaterally for $20 \mathrm{~min}$ with normal medium (solid symbols) or with medium containing $20 \mu \mathrm{M}$ bumet-
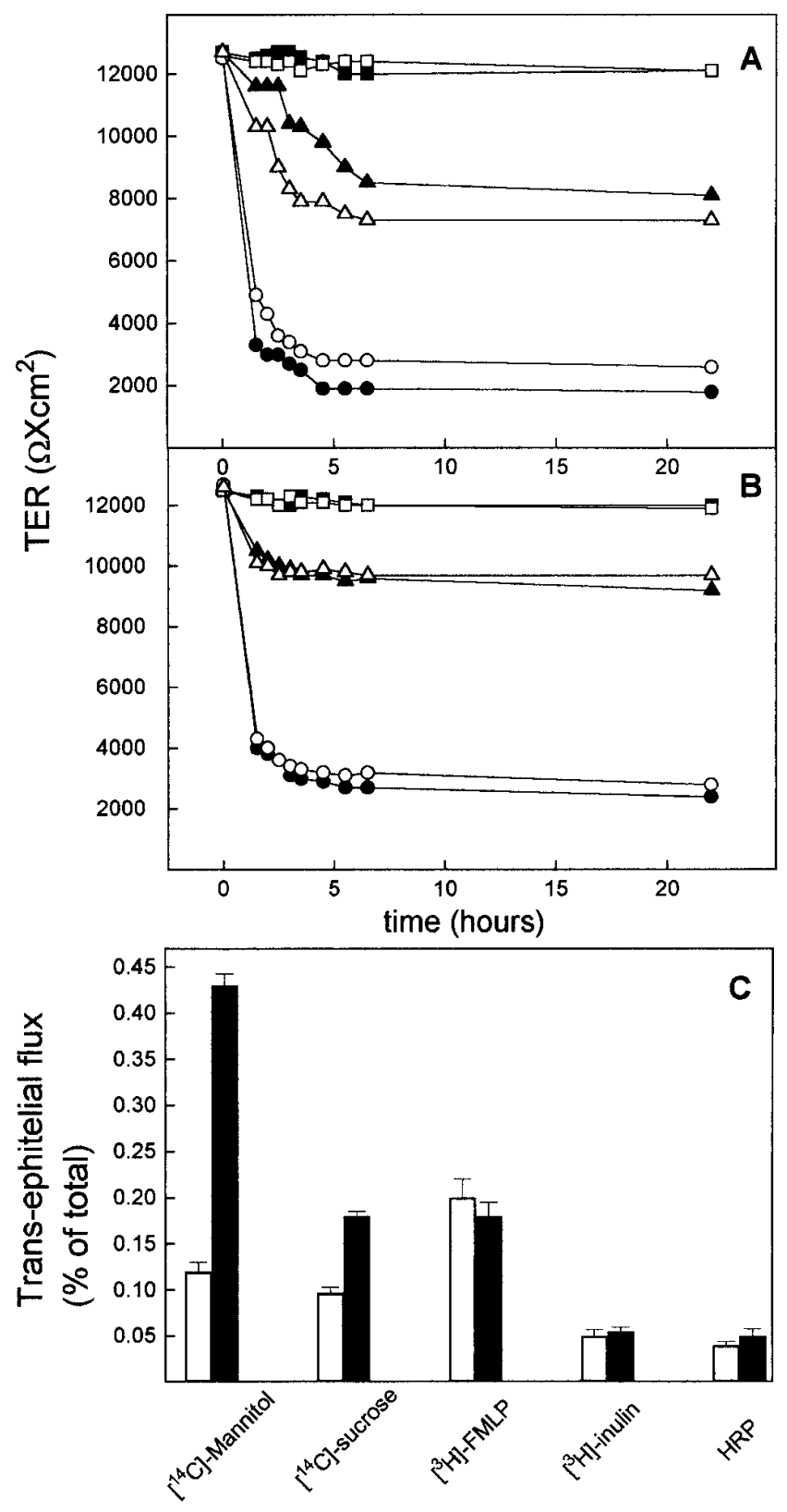

anide (open symbols) and then incubated apically with no toxin (squares), nonactivated $100 \mathrm{nM}$ VacA (triangles) and $100 \mathrm{nM}$ VacA preactivated at $\mathrm{pH} 2.0$ (circles). (B) The basolateral chamber of MDCK cell monolayers was filled with chloride containing medium (solid symbols) or with an equivalent medium where chloride was substituted for the membrane nonpermeable anion gluconate (open symbols). Cells were then treated apically, as described above, with VacA diluted in the same media with or without chloride and TER was measured at the indicated times. Data are from a representative experiment of three. $(C)$ After $24 \mathrm{~h}$ incubation, $\left[{ }^{14} \mathrm{C}\right]$-mannitol $(0.25$ $\mu \mathrm{Ci} / \mathrm{ml}),\left[{ }^{14} \mathrm{C}\right]$-sucrose $(20 \mu \mathrm{Ci} / \mathrm{ml}),\left[{ }^{14} \mathrm{C}\right]$-f-MLP $(2 \mu \mathrm{Ci} / \mathrm{ml}),\left[{ }^{3} \mathrm{H}\right]$-inulin $(20 \mu \mathrm{Ci} / \mathrm{ml})$, or HRP $(0.2 \mathrm{mg} / \mathrm{ml})$ were added to the lower filter chamber of control (white columns) and toxin treated (black columns) MDCK cell monolayers. After $24 \mathrm{~h}$, radioactivity and HRP activity were determined in the upper filter chamber. Data are expressed as percent of total radioactivity or HRP activity and are the mean of two experiments run in duplicate. The basal transepithelial flux of $\left[{ }^{14} \mathrm{C}\right]-\mathrm{f}-\mathrm{MLP}$ was consistently higher than that of other tested tracers, possible due to a small contribution by a transepithelial pathway. Bars are ranges. 


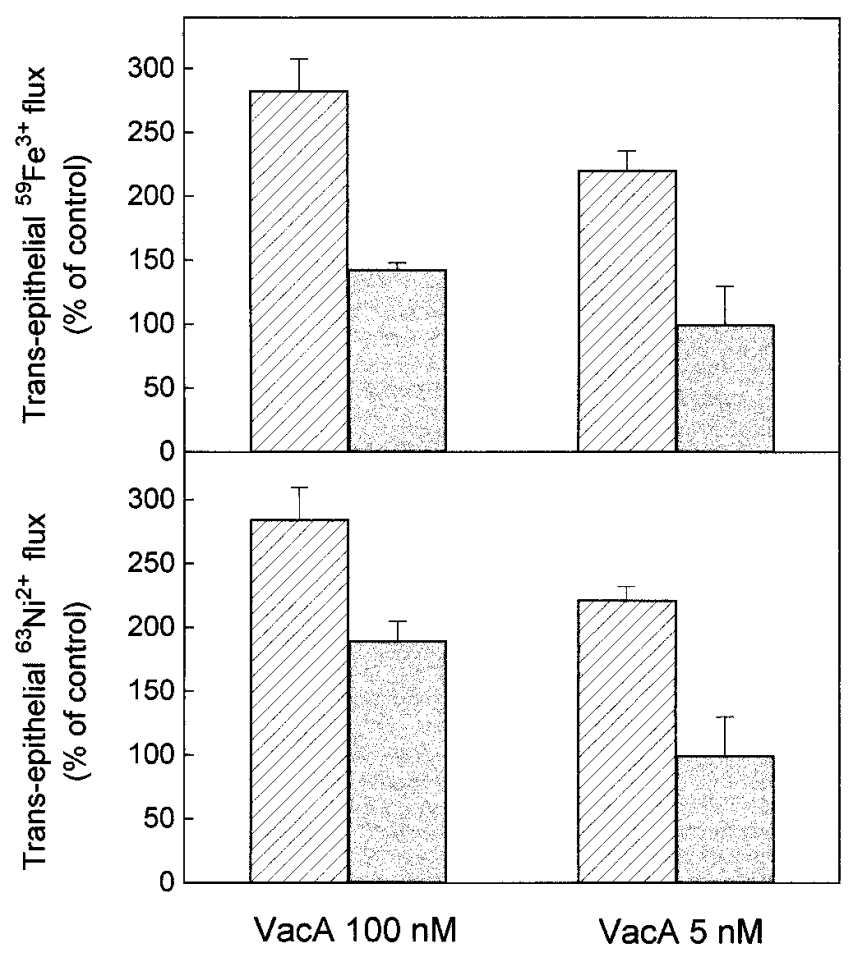

Figure 5. Increased flux of $\mathrm{Fe}^{3+}$ and $\mathrm{Ni}^{2+}$ through monolayers of MDCK cells induced by VacA. MDCK monolayers were treated with indicated doses of VacA pre-incubated at $\mathrm{pH} 2.0$ (hatched columns) or $\mathrm{pH} 7.4$ (grey columns) for $24 \mathrm{~h} .{ }^{59} \mathrm{Fe}^{3+}(1.6 \mu \mathrm{Ci} / \mathrm{ml})$ or ${ }^{63} \mathrm{Ni}^{2+}(4.4$ $\mu \mathrm{Ci} / \mathrm{ml})$ were added to the lower filter chamber in DMEM medium, without carbonate, plus 5\% FCS and $10 \mathrm{mM} \mathrm{Na}$-Hepes, pH 7.4. Radioactivity was then collected after an additional $24 \mathrm{~h}$ incubation from the upper chamber. Data are expressed as percent increase transepithelial flux with respect of control monolayers (treated with no toxin), and are the mean of two experiments run in duplicate. Bars represent range.

VacA induces fluxes of $\mathrm{Fe}^{3+}$ and $\mathrm{Ni}^{2+}$ across epithelial cell monolayers. $\mathrm{Fe}^{3+}$ is required for optimal microbial growth, whereas $\mathrm{Ni}^{2+}$ is an essential component of $H$. pylori urease, an enzyme necessary for $H$. pylori colonization of the stomach $(38,39)$. This enzyme hydrolyses urea with the production of ammonia, which buffers the acid environment around the bacteria and provides a nitrogen source (38). Fig. 5 shows that VacA increased the permeability of MDCK cells to both $\mathrm{Fe}^{3+}$ and $\mathrm{Ni}^{2+}$. Again, the relative increase of ions permeability paralleled the increased diffusion of the paracellular tracer mannitol, indicating that intercellular junctions became leaky to these ions.

Effect of VacA on tight and adherent junctions. The results described above suggest that acid-activated VacA alters the permeability of epithelial cell monolayers via modification of transmembrane protein complexes that mediate cell-to-cell adhesion. ZO-1, occludin, and cingulin are well-characterized major components of the TJ, whereas E-cadherin is associated to the adherent junction (40-42). Their distribution in control and toxin-treated cell monolayers was determined by indirect immunofluorescence analysis with specific antibodies in MDCK cells (Fig. 6). High-resolution reconstruction of XZ planes (orthogonal to the epithelial plane) showed no difference in the spatial distribution of ZO-1 and E-cadherin upon
Xz plane

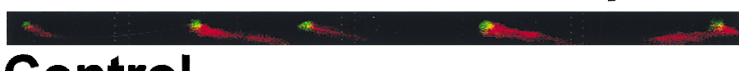

\section{Control}

\section{VacA}

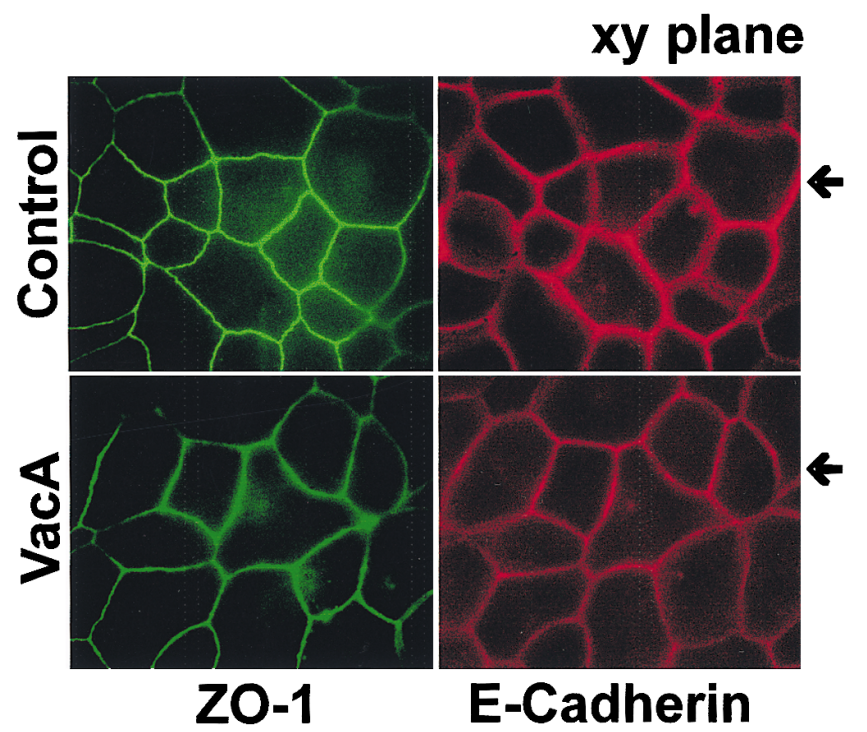

Figure 6. Effect of VacA on the distribution of ZO-1 and E-cadherin in MDCK cells. Cell monolayers were treated with VacA $(200 \mathrm{nM})$ preactivated at $\mathrm{pH} 2.0$ or with no toxin (control) for $24 \mathrm{~h}$, fixed and permeabilized. The distribution of ZO-1 (green) and E-cadherin (red) was determined by indirect immunofluorescence microscopy using specific antibodies. Fluorescence optical sections (XY planes) parallel to the epithelial plane of $0.5 \mu \mathrm{m}$ were collected and $\mathrm{XZ}$ planes, perpendicular to the cell monolayers, were reconstructed after deconvolution, and merged. The positions of shown $\mathrm{XZ}$ planes are indicated by arrows in the XY sections.

toxin treatment. In fact, ZO-1 remains localized in the upper apical region of intercellular interfaces corresponding to TJs, while E-cadherin remains present in a basolateral region just below ZO-1, as expected for adherent junctions. XY planes (parallel to the epithelial plane) analysis showed no modification of the continuity and normal distribution of either ZO-1 or E-cadherin. A similar analysis conducted on other TJ-associated proteins occludin and cingulin failed to reveal any alteration (not shown). Thus, VacA-induced increase of the paracellular conductivity is not due to an alteration of intercellular adhesion complexes detectable by immunofluorescence. Accordingly, VacA did not modify either the electrophoretic mobility or the total amount of occludin, ZO-1 and E-cadherin (Fig. 7).

VacA does not induce either intracellular vacuolation or a defect of EGF degradation in epithelial monolayers. The characteristic activity of VacA on cultured cells consists in the induction of intracellular vacuoles (10). However, VacA induced negligible vacuolization in polarized MDCK cells, while, in the very same conditions, nonpolarized MDCK cells developed extensive vacuolar degeneration (Fig. 8). In both MDCK and T84 cell monolayers, VacA induced only a minor increase of neutral red uptake $(50 \%)$, independent of low $\mathrm{pH}$ activation (Fig. $8 \mathrm{D}$ ). This value should be compared with the eight- to 


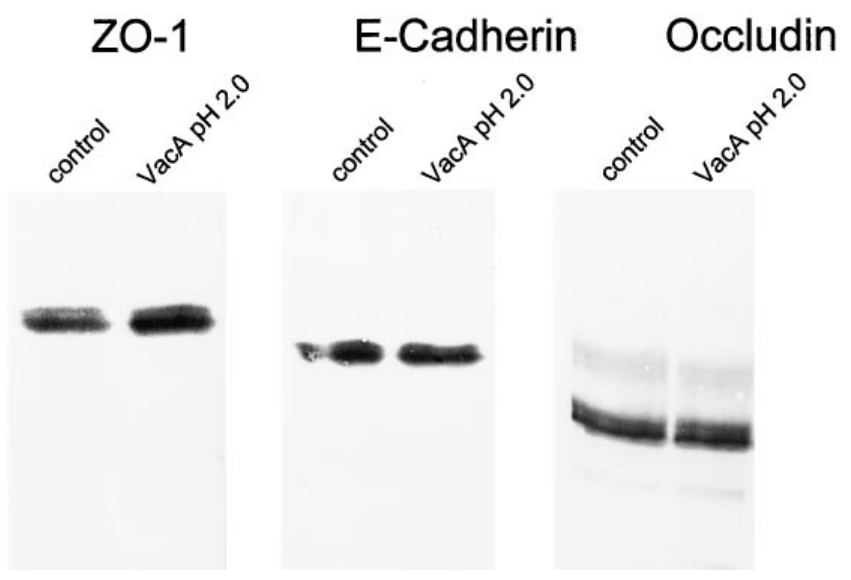

Figure 7. Western blot of ZO-1, E-cadherin, and occludin. Total proteins from MDCK cell monolayers treated as described in the legend of Fig. 6, were dissolved and run on SDS-PAGE. ZO-1, E-cadherin, and occludin were identified by Western blot after transfer on nitrocellulose with specific antibodies.

tenfold increase in neutral red uptake by fully vacuolated nonpolarized MDCK and T84 cells and of HeLa cells. In these latter cell lines, the degradation of EGF is inhibited before vacuoles become apparent (18). Hence, to assay for functional
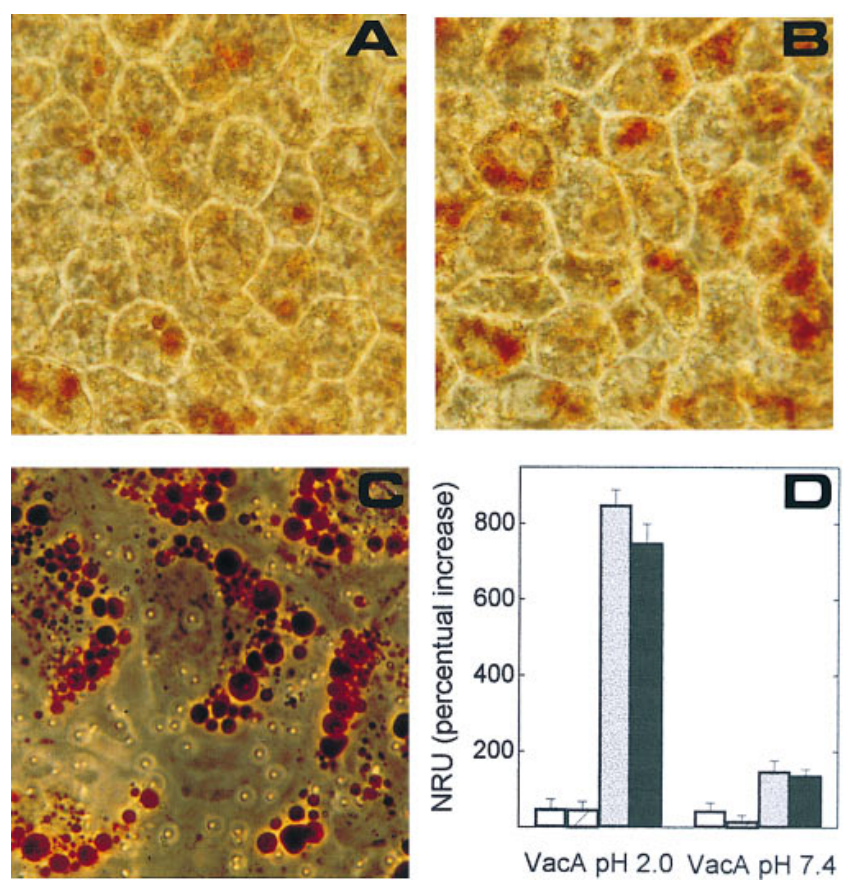

Figure 8. Intracellular vacuolation in polarized and nonpolarized cells following VacA treatment. MDCK cells were either allowed to form polarized epithelia ( $A$ and $B$ ) or grown sparse $(C)$ on carbonate filters. After a $24 \mathrm{~h}$ incubation with normal medium $(A)$ or with VacA $(200 \mathrm{nM})(B$ and $C)$, cells were incubated with neutral red, washed, and photographed. Magnification is $100 . D$ shows quantification of neutral red uptake (NRU) in monolayers formed by polarized T84 (white columns) and MDCK (hatched columns) cells and in nonpolarized T84 (shaded columns) and MDCK (black columns), after treated for $24 \mathrm{~h}$ with $\mathrm{VacA}(200 \mathrm{nM})$ preincubated at $\mathrm{pH} 7.4$ or at $\mathrm{pH}$ 2.0 , as indicated.

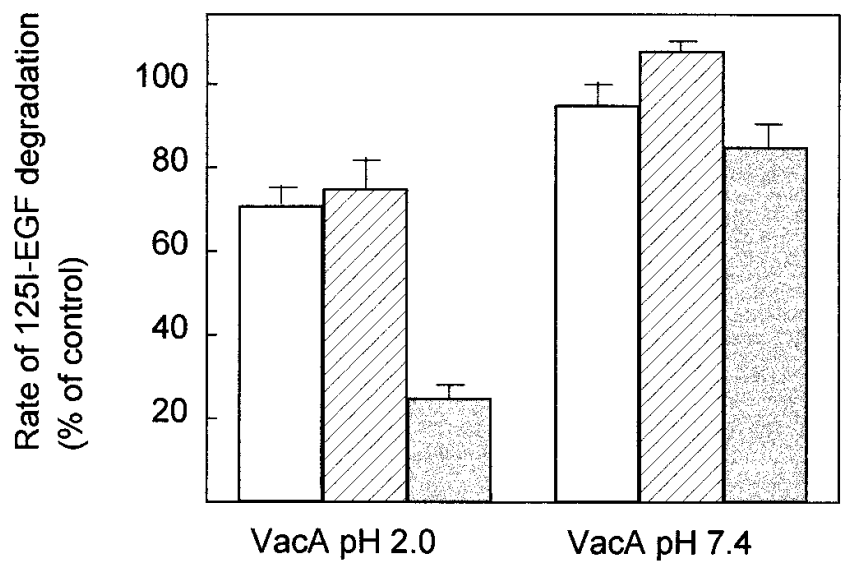

Figure 9. EGF degradation by polarized T84 and MDCK cell monolayers treated with VacA. Monolayers formed by T84 (white columns) and MDCK (hatched columns) cells or HeLa cells (shaded columns) were treated with VacA pretreated at $\mathrm{pH} 7.4$ or 2.0 , as described in the legend of Fig. 8. The rate of ${ }^{125}$ I-EGF degradation was determined as described in the Method section, and expressed as percentage of control (cells not treated with VacA) values. Data are the mean of three experiments run in duplicate. Bars represent range.

alterations of the endocytic pathway, EGF degradation in epithelial monolayers was determined. ${ }^{125}$ I-EGF was added to the basolateral side of T84 and MDCK monolayers, previously exposed or nonexposed to VacA, and its intracellular degradation was monitored by following the appearance of TCA-soluble radioactive peptides in the upper and lower chambers. Cells exposed to activated VacA degrade ${ }^{125}$ I-EGF only slightly less efficiently than control cells (Fig. 9). Incidentally, we found that EGF derived TCA soluble ${ }^{125}$ I-peptides, having a maximal molecular weight of 2,000-3,000, are not released into the upper filter chamber after VacA intoxication (not shown), consistent with the previous observation that the permeability to molecules with molecular weight $>350-450$ is not increased by the toxin.

VacA-induced formation of intracellular vacuoles depends on the activity of the V-ATPase, and is counteracted by $\mathrm{Na}^{+} / \mathrm{K}^{+}$ ATPase activity and therefore is prevented by bafilomycin A1 and enhanced by ouabain $(11,12)$. However, neither bafilomycin A1 nor ouabain affected the decrease of TER of MDCK cells monolayers induced by nonactivated or low $\mathrm{pH}$ activated VacA (not shown).

\section{Discussion}

The present work shows that $H$. pylori VacA toxin decreases the TER of epithelial cell monolayers and increases the monolayer permeability to mannitol and, to a lower extent, sucrose, suggesting a modification of the paracellular route. The resistance of this pathway, limited to the space comprised between adjacent epithelial cells, is likely to be regulated by TJs primarily, but also by the adherent junction protein E cadherin (4042). We provide multiple evidence that VacA increases the transepithelial diffusion of ions and small uncharged molecules via a selective modulation, rather than via disruption of intercellular junctions or cellular cytotoxicity subsequent to vacuolation: 1.) junctional disruption virtually abolishes TER, while VacA never lowers TER below the minimal value of 1,000 
$1,200 \Omega \times \mathrm{cm}^{2}$, a value considered consistent with the presence of functional TJs; accordingly Caco- 2 cells, whose physiological TER is lower than $1,000 \Omega \times \mathrm{cm}^{2}$, are not affected by VacA; 2.) transepithelial diffusion of molecules with molecular weight $>350-450$ is not modified; 3 .) the distribution and the total amount of TJ proteins ZO-1, occludin and cingulin and of the adherent junction protein E-cadherin is not affected by VacA; 4.) there is no increase in the size of acidic intracellular compartments in VacA-treated epithelial monolayers and ${ }^{125}$ I-EGF degradation is slightly modified. Moreover, a TER decrease due to VacA increasing apical ion secretion can be excluded, because blocking chloride flow through the basolateral membrane, either by inhibiting the $\mathrm{K} / \mathrm{Na} / 2 \mathrm{Cl}$ cotransporter with bumetaninde or by substituting chloride for the membrane nonpermeable anion gluconate, had no effect.

Modulation of paracellular permeability without apparent loss of intercellular junction integrity is consistent with previous studies indicating that receptor ligands, protein kinases and secondary messengers can influence their functions (4143). Immunofluorescence with antibodies to phosphotyrosine revealed that VacA did not modify significantly the level and distribution of Tyr-phosphorylation of the proteins involved in the intercellular junctional complexes (not shown). A result that is relevant in defining the type of VacA-induced alteration described here is that only when cell monolayer TER values are $>1,000-1,300 \Omega \times \mathrm{cm}^{2}$ can they be modified and lowered to the same final value, irrespective of the different cell lines tested here. This may indicate that the molecular lesion caused by the toxin is the same in different cell types and that the toxin acts on a cell mechanism implicated in the tight sealing of cell monolayers. Such a device may be absent in Caco- 2 cells, characterized by TER values $<1,000 \Omega \times \mathrm{cm}^{2}$, and it may not have been properly assembled in T84 cells exposed to $H$. $p y$ lori in a recent study, where the starting TER value was 1,500 $\Omega \times \mathrm{cm}^{2}$ (44). In this respect, the highly impermeable MDCK cells monolayers $\left(12,000-17,000 \Omega \times \mathrm{cm}^{2}\right)$ appear to be the best cellular model to study VacA effects on epithelial permeability. Moreover, the present study provides an important contribution toward the development of in vitro systems capable of defining the biological activity of VacA without using animals. In fact, the measurement of TER of MDCK cell monolayers is quantitative, highly reproducible, and inexpensive and provides the possibility of measuring the kinetics of the toxin effect. The relevance of this canine cellular model to study VacA toxicity is further emphasized by the fact that $H$. pylori can infect dogs (45), closely reproducing the typical symptoms and pathological changes observed in human gastritis (G. del Giudice, personal communication).

$\mathrm{VacA}$ is defined as a toxin causing cell vacuolation. However, no vacuoles were detected, and, more importantly, no functional defect of the endocytic pathway could be revealed in polarized epithelial monolayers. These observations pose the problem of the relationship between the well-established vacuolated phenotype and TER decrease. Although both cellular lesions depend on acid activation of VacA (21; this work), implicating the same acid structure of $\operatorname{VacA}(21,22)$, the two toxic effects differs pharmacologically, the former being sensitive while the latter is insensitive to bafilomycin A1 and ouabain treatment. Hence, either VacA acts on different cellular targets or it affects a single factor with pleiotropic effects on both the endocytic pathway and epithelial permeability. This latter possibility is supported by the fact that VacA- induced cell vacuolation is dependent on cell density and is hardly detectable in cells grown at confluence (our unpublished results).

VacA was recently shown to enter intracellular vesicular structures (46) and to be able to act from cytosol (47). This suggests that the active domain of the toxin may gain access to the cell cytosol from intracellular compartments, after endocytosis, as A-B type protein toxins do. However, the lack of V-ATPase requirement for VacA-dependent TER decrease clearly indicates that such putative translocation into the target cell does not require endosomal acidification, as it is the case for A-B toxins like diphtheria and tetanus toxins (24).

Activation of VacA can occur at $\mathrm{pH}$ 2.0, a value typical of the gastric juice, but it is also achieved at the milder $\mathrm{pH}$ values present below the mucus layer present on gastric cells (48). This finding is particularly relevant with respect to the fact that VacA is presumably released above the apical domain of gastric epithelial cells, below the mucus layer. Although these data indicate that toxin activation does not require diffusion into the stomach lumen, activated VacA, which is resistant to very acidic $\mathrm{pH}$ values and to proteolysis by pepsin (47), may survive for some time the harsh conditions of the stomach lumen and therefore act at a distance from the site of release.

A central issue in the study of the biological activity of natural toxins is the understanding of their adaptive role in the strategy of survival of toxin producing species. Because the reduced nutrient supply below the mucus layer, where $H$. pylori is mainly localized, may limit its growth in vivo, a moderate loosening of intercellular junctions, resulting in an increased diffusion of metabolites and required elements, is expected to provide a selective advantage to toxigenic strains. Indeed, $\mathrm{Fe}^{3+}$, a critical element for microbial growth, and whose availability is strictly kept under control by the host, flows faster through epithelial cells monolayers treated with VacA. VacA also promotes the diffusion of $\mathrm{Ni}^{2+}$, which is the urease active site metal ion (49). Urease is essential for $H$. pylori colonization of the stomach mucosa and a specific $\mathrm{Ni}^{2+}$-binding protein $(39,50)$ regulates the urease gene transcription. The paracellular transepithelial diffusion of potential metabolic substrates for $H$. pylori, such as glucose or amino acids, is similarly expected to be increased by VacA action, their size being comparable with that of mannitol. On the other hand, prevention of the diffusion of even slightly larger bacterial molecules, such as formylated peptides and larger molecules potentially able to recruit inflammatory cells, is maintained. Such selective action of VacA, without acute cytotoxic effects, is indeed peculiar and might have evolved to ensure maximal advantage for $H$. pylori infecting cells, with minimal inflammatory response, in keeping with the notion that escaping host defensive reactions is a main strategy of $H$. pylori (2).

\section{Acknowledgments}

We thank Drs. Maurizio Molinari and Vladimir Pelicic for critically reading the manuscript and Dr. Sandra Citi for helpful suggestions.

This work was supported by European Community grants (TMR FMRX CT96 0004 and Biomed BMH4 CT97 2410), by MURST $60 \%$ and $40 \%$, by the CNR Target Project "Biotechnologie" 97.01168.PF49, by a research grant from the Giovanni Armenise-Harvard Foundation for Advanced Scientific Research and is in partial fulfillment of the doctorate degree in Cellular and Molecular Biology and Pathology of the University of Padova by Barbara Satin. 


\section{References}

1. Warren, J.R., and B.J. Marshall. 1983. Unidentified curved bacilli on gastric epithelium in active chronic gastritis. Lancet. 1:1273-1275.

2. Blaser, M.J. 1993. Helicobacter pylori: microbiology of a "slow" bacterial infection. Trends Microbiol. 1:255-259.

3. Eurogast Study Group. 1993. An international association between Helicobacter pylori infection and gastric cancer. Lancet. 341:1359-1362.

4. Parsonnet, J., S. Hansen, L. Rodriguez, A. Gelb, A. Warnke, E. Jellum, N. Orentreich, J. Vogelman, and G. Friedman. 1994. Helicobacter pylori infection and gastric lymphoma. N. Engl. J. Med. 330:1267-1271.

5. Xiang, Z., S. Censini, P.F. Bayeli, J.L. Telford, N. Figura, R. Rappuoli, and A. Covacci. 1995. Analysis of expression of CagA and VacA virulence factors in 43 strains of $H$. pylori reveals that clinical isolates can be divided into two major types and that CagA is not necessary for expression of the vacuolating cytotoxin. Infect. Immun. 63:94-98.

6. Censini, S., C. Lange, Z. Xiang, J.E. Crabtree, P. Ghiara, M. Borodovsky, R. Rappuoli, and A. Covacci. 1996. Cag, a pathogenicity island of Helicobacter pylori, encodes type I-specific and disease-associated virulence factors. Proc. Natl. Acad. Sci. USA. 93:14648-14653.

7. Covacci, A., S. Censini, M. Bugnoli, R. Petracca, D. Burroni, G. Macchia, A. Massone, E. Papini, Z. Xiang, H. Figura, and R. Rappuoli. 1993. Molecular characterization of the $128-\mathrm{kDa}$ immunodominant antigen of Helicobacter pylori associated with cytotoxicity and duodenal ulcer. Proc. Natl. Acad. Sci. USA. 90:5791-5795

8. Crabtree, J.E., A. Covacci, S.M. Farmery, Z. Xiang, D.S. Tompkins, S. Perry, I.J.D. Lindey, and R. Rappuoli. 1995. Helicobacter pylori induced interleukin-8 expression in gastric epitheliel cells is associated with CagA positive phenotype. J. Clin. Pathol. 48:41-45.

9. Leunk, R.D., P.T. Johnson, B.C. David, W.G. Kraft, and D.R. Morgan. 1988. Cytotoxin activity in broth-culture filtrates of Campylobacter pylori. J. Med. Microbiol. 26:93-99.

10. Cover, T.L., and M.J. Blaser. 1992. Purification and characterization of the vacuolating toxin from Helicobacter pylori. J. Biol. Chem. 267:10570-10575.

11. Cover, T.L., L.Y. Reddy, and M.J. Blaser. 1993. Effects of ATPase inhibitors on the response of HeLa cells to Helicobacter pylori vacuolating toxin. Infect. Immun. 61:1427-1431.

12. Papini, E., M. Bugnoli, M. De Bernard, N. Figura, R. Rappuoli, and C. Montecucco. 1993. Bafilomycin A1 inhibits Helicobacter pylori-induced vacuolization of HeLa cells. Mol. Microbiol. 7:323-327.

13. Papini, E., M. De Bernard, M. Bugnoli, E. Milia, R. Rappuoli, and C. Montecucco. 1993. Cell vacuolization induced by Helicobacter pylori: inhibition by bafilomycins A1, B1, C1, and D. FEMS Microbiol. Letters. 113:155-159.

14. Papini, E., E. Gottardi, B. Satin, M. de Bernard, J. Telford, P. Massari, R. Rappuoli, S.B. Sato, and C. Montecucco. 1996. The vacuolar ATPase proton pump on intracellular vacuoles induced by Helicobacter pylori. J. Med. Microbiol. 44:1-6.

15. Papini, E., M. De Bernard, E. Milia, M. Bugnoli, M. Zeriar, R. Rappuoli, and C. Montecucco. 1994. Cellular vacuoles induced by Helicobacter pylori originate from late endosomal compartments. Proc. Natl. Acad. Sci. USA. 9117:9720-9724.

16. Molinari, M., C. Galli, N. Norais, J.L. Telford, R. Rappuoli, J.P. Luzio, and C. Montecucco. 1997. Vacuoles induced by Helicobacter pylori toxin contain both late endosomal and lysosomal markers. J. Biol. Chem. 272:25339_ 25344

17. Papini, E., B. Satin, C. Bucci, M. de Bernard, J.L. Telford, R. Manetti, R. Rappuoli, M. Zerial, and C. Montecucco. 1997. The small GTP binding protein rab7 is essential for cellular vacuolation induced by Helicobacter pylori cytotoxin. EMBO 16:15-24.

18. Satin, B., N. Norais, J.L. Telford, R. Rappuoli, M. Murgia, C. Montecucco, and E. Papini. 1997. Effect of Helicobacter pylori vacuolating toxin on maturation and extracellular release of procathepsin D and on epidermal growth factor degradation. J. Biol. Chem. 272:25022-25028.

19. Molinari, M., M. Salio, C. Galli, N. Norais, R. Rappuoli, A. Lanzavecchia, and C. Montecucco. 1998. Selective inhibition of Li-dependent antigen presentation by Helicobacter pylori toxin VacA. J. Exp. Med. 187:135-140.

20. Cover, T.L. 1997. The vacuolating cytotoxin of Helicobacter pylori. Mol. Microbiol. 20:241-246.

21. Cover, T.L., P.I. Hanson, and J.E. Heuser. 1997. Acid-induced dissociation of VacA, the Helicobacter pylori vacuolating toxin, reveals its pattern of assembly. J. Cell Biol. 138:759-769.

22. De Bernard, M., E. Papini, V. de Filippis, E. Gottardi, J. Telford, R. Manetti, A. Fontana, R. Rappuoli, and C. Montecucco. 1995. Low pH activates the vacuolating toxin of Helicobacter pylori, which becomes acid and pepsin resistant. J. Biol. Chem. 270:23937-23940.

23. Telford, J.L., P. Ghiara, M. Dell'Orco, M. Comanducci, D. Burroni, M. Bugnoli, M.F. Tecce, S. Censini, A. Covacci, Z. Xiang, et al. 1994. Purification and characterization of the vacuolating toxin from Helicobacter pylori. J. Exp. Med. 179:1653-1658.
24. Montecucco, C., E. Papini, and G. Schiavo. 1994. Bacterial protein toxins penetrate cells via a four-step mechanism. FEBS Lett. 346:92-98.

25. Eaton, S., and K. Simons. 1995. Apical, basal, and lateral cues for epithelial polarization. Cell. 82:5-8.

26. Gumbiner, B. 1987. Structure, biochemistry, and assembly of tight junctions. Am. J. Physiol. 253:C749-C758.

27. Kraehenbuhl, J.P., and M.R. Neutra. 1992. Molecular and cellular basis of immune protection of mucosal surfaces. Physiol. Rev. 72:853-879.

28. Fuller, S., C.H. von Bonsdorf, and K. Simons. 1984. Vesicular stomatitis virus infects and matures only through the basolateral surface of the polarized epithelial cell line, MDCK. Cell. 38:65-77.

29. Dharmsathphorn, K., and J.L. Madara. 1990. Established intestinal cell lines as model systems for electrolyte transport studies. Methods Enzymol. 192: 354-389.

30. Chantret, I., A. Barbat, E. Dussaulx, M.G. Brattain, and A. Zweibaum. 1988. Epithelial polarity, villin expression, and enterocytic differentiation of cultured human colon carcinoma cells: a survey of twenty cell lines. Cancer Res. 48:1936-1942.

31. Lopez-Barahona, M., I. Fialka, J.M. Gonzalez-Sancho, M. Asuncion, M. Gonzalez, T. Iglesias, J. Bernal, H. Beug, and A. Munoz. 1995. Thyroid hormone regulates stromelysin expression, protease secretion and the morphogenetic potential of normal polarized mammary epithelial cells. EMBO J. 14: 1145-1155.

32. Manetti, R., P. Massari, D. Burroni, M. de Bernard, A. Marchini, R. Olivieri, E. Papini, C. Montecucco, R. Rappuoli, and J.L. Telford. 1995. Helicobacter pylori cytotoxin: importance of native conformation for induction of neutralizing antibodies. Infect. Immun. 63:4476-4480.

33. Steinman, R.M., S.E. Brodie, and Z.A. Chon. 1976. Membrane flow during pinocytosis. A stereological analysis. J. Cell. Biol. 68:665-687.

34. Bradford, M.M. 1976. A rapid and sensitive method for the quantitation of microgram quantities of protein utilizing the principle of protein-dye binding. Anal. Biochem. 72:248-254.

35. Laemmli, U.K. 1970. Cleavage of structural proteins during the assembly of head of bacteriophage T4. Nature. 227:680-685.

36. Gazitua, S., and J.W. Robinson. 1982. Ion fluxes and electrical characteristics of the short-circuited rat colon in vitro. Pflugers Arch. 394:32-37.

37. Eaton, K.A., C.L. Brooks, D.R. Morgan, and S. Krakowka. 1991. Essential role of urease in pathogenesis of gastritis induced by helicobacter pylori in gnotobiotic piglets. Infect. Immun. 59:2470-2475.

38. Labigne, A., V. Cussac, and P. Courcoux. 1991. Shuttle cloning and nucleotide sequences of Helicobacter pylori genes responsible for urease activity. J. Bacteriol. 173:1920-1931.

39. Tsuda, M., M. Karita, M.G. Morshed, K. Okita, and T. Nakazawa. 1994 A urease-negative mutant of Helicobacter pylori constructed by allelic exchange mutagenesis lacks the ability to colonize the nude mouse stomach. Infect. Immun. 62:3586-3589.

40. Rajasekaran, A.K., M. Hojo, T. Huima, and E. Rodriguez-Boulan. 1996 Catenins and Zonula Occludens-1 form a complex during stages in the assembly of tight junctions. J. Cell. Biol. 132:451-463.

41. Madara, J.L. 1988. Tight junction dynamic: is paracellular transport regulated? Cell. 53:497-498.

42. Rubin, L.L. 1992. Endothelial cells: adhesion and tight junctions. Curr. Opin. Cell Biol. 4:830-833.

43. Turner, J.R., B.K. Rill, S.L. Carlson, D. Carnes, R. Kerner, R.J. Mrsny, and J.L. Madara. 1997. Physiological regulation of epithelial tight junctions is associated with myosin light-chain phosphorylation. Am. J. Physiol. 173:C1378C1385.

44. Corthesy-Theulaz, I., N. Porta, E. Pringault, L. Racine, A. Bogdanova, J.P. Kraehenbuhl, A.L. Blum, and P. Michetti. 1996. Adhesion of Helicobacter pylori to polarized T84 human intestinal cell monolayers is $\mathrm{pH}$ dependent. Infect. Immun. 64:3827-3832.

45. Radin, M.J., K.A. Eaton, S. Krakowka, D.R. Morgan, A. Lee, G. Otto, and J. Fox. 1990. Helicobacter pylori gastric infection in gnotobiotic beagle dogs. Infect. Immun. 58:2606-2612.

46. Garner, J.A., and T.L. Cover. 1996. Binding and internalization of the Helicobacter pylori vacuolating cytotoxin by epithelial cells. Infect. Immun. 46 : 4197-4203.

47. De Bernard, M., B. Arico', E. Papini, R. Rizzuto, G. Grandi, R. Rappuoli, and C. Montecucco. 1997. Helicobacter pylori toxin VacA induces vacuole formation by acting in the cell cytosol. Mol. Microbiol. 26:665-674.

48. Schade, C., G. Flemstrom, and L. Holm. 1994. Hydrogen ion concentration in the mucus layer on top of acid-stimulated and -inhibited rat gastric mucosa. Gastroenterology. 107:180-188.

49. Jabri, E., M.B. Carr, R.P. Hausinger, and P.A. Karplus. 1995. The crystal structure of urease from Klebsiella aerogenes. Science. 268:998-1004.

50. Mobley, H.L.T., R.M. Garner, and P. Bauerfeind. 1995. Helicobacter pylori nickel-transport gene nixA: synthesis of catalytically active urease in Escherichia coli independent of growth conditions. Mol. Microbiol. 16:97-109. 